\title{
Characteristic Evaluation of Organic Light-Emitting Diodes Prepared with Stamp Printing Technique
}

\author{
Apisit Chittawanij and Kitsakorn Locharoenrat \\ Department of Physics, Faculty of Science, King Mongkut's Institute of Technology Ladkrabang, Bangkok 10520, Thailand \\ Correspondence should be addressed to Kitsakorn Locharoenrat; kitsakorn.lo@kmitl.ac.th
}

Received 16 March 2017; Accepted 11 April 2017; Published 10 May 2017

Academic Editor: Kiyokazu Yasuda

Copyright (c) 2017 Apisit Chittawanij and Kitsakorn Locharoenrat. This is an open access article distributed under the Creative Commons Attribution License, which permits unrestricted use, distribution, and reproduction in any medium, provided the original work is properly cited.

\begin{abstract}
We have reported on a stamp printing technique that uses PET release film as a printing stamp to deposit TPBi thin film served as the electron transport layer of the organic light-emitting diodes. TPBi thin film was printed with a good uniformity and resolution. Effect of deposition conditions on optical and electrical properties and surface roughness of TPBi thin film have been studied under spectroscopy and atomic force microscopy, respectively. It is found that characteristic of TPBi thin film is improved via controlled stamp temperature and time. Since TPBi thin film exhibits the surface morphology comparable to that of conventional spin-coating thin film, our findings suggest that PET release film-based stamp printing approach is possible to use as an alternative deposition of the organic thin film as compared with a traditional one.
\end{abstract}

\section{Introduction}

Properties of organic light-emitting devices or OLEDs especially in the optoelectronic applications show some benefits in terms of common structure, low-driving voltage, and flexible as well as high throughput $[1,2]$. In the solution-based OLEDs, there is a dissolution limitation of the individual layer in order to form the multilayers $[3,4]$. To solve this issue, different printing approaches have been introduced [5-8]. Stamp printing methods are one of the fabrication techniques in which the stacking multilayer is needed [9]. For instance, Choi et al. have demonstrated transferring of a completed OLED structure from a patterned mold [10]. This technique, ready fabrication of solution-processed organic materials, was also reported by Ferenczi et al. [11]. Similarly, Chen et al. have demonstrated a new PDMS stamp, which was simultaneously used to define the lateral patterns [12]. PDMSbased printing was also used to structure OLED components $[13,14]$. However, a few limitations of PDMS-based printing are still remaining [15-20].

Recently, one demonstrates that, by controlling the surface polarity and stiffness of stamp, thin film is replicated to get better resolution and uniformity [21]. Release film (RF) stamp method is one of the easiest processes to fabricate the organic materials together with the uniform layers. Although we are able to use PET release film stamp material, a detailed investigation of the stamp printing by RF has not been reported yet. Therefore, the further study is necessary to improve the use of RF to form the multilayer of OLEDs device.

In this study, an electron transport layer (ETL) of soluble OLEDs is developed using a PET release film (RF) stamp printing method by varying stamping time and temperature of the deposited TPBi. Effects of these parameters on physical, optical, and electrical properties of TPBi thin film are studied and discussed. All organic layers stacked without any intermixing of electron transport layer by the stamp printing method are also demonstrated.

\section{Materials and Methods}

2.1. Materials. (1) Indium Tin Oxide (ITO) coated glass was used as a conductive transparent material because it is very easy to clean, available on large scale, and easy to structure as a substrate. 


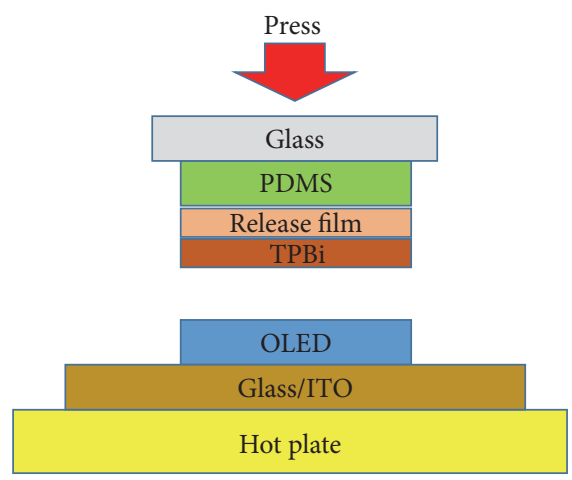

(a)
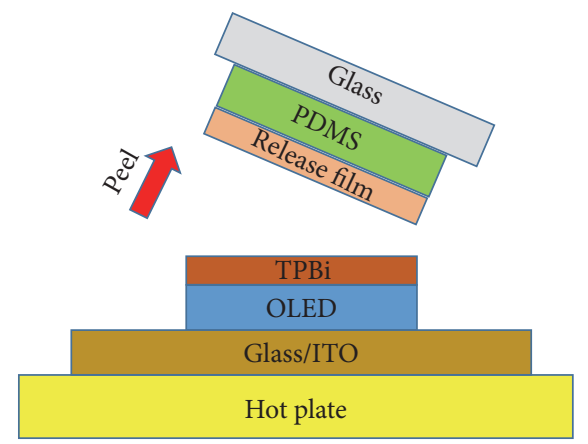

(b)

FIGURE 1: Schematic illustration of release film stamping processes: (a) pressing stamp and (b) peeling stamp.

(2) We used poly(3,4-ethylenedioxythiophene) poly(styrenesulfonate) (PEDOT:PSS) because of the good filmforming properties in terms of a hole transport layer (HTL) [22]. It was also served as an ameliorating coating for ITO as it allowed us to overcome a lot of drawbacks of ITO by raising its work function from 4.8 to $5.2 \mathrm{eV}$ [23].

(3) We used 2,6-bis(3-(9H-carbazol-9-yl)phenyl)pyridine (26DCzPPy) $\left(\mu_{h}, \mu_{e}=10^{-5} \mathrm{~cm}^{2} / \mathrm{Vs}\right)[24,25]$ and bis(3,5-difluoro-2-(2-pyridyl)phenyl-(2-carboxypyridyl) iridium III) (FIrpic) served as bipolar host and blue dopant, respectively.

(4) We used $2,2^{\prime}, 2^{\prime \prime}$-(1,3,5-benzinetriyl)-tris(1-phenyl-1$\mathrm{H}$-benzimidazole) (TPBi) as an electron transport material, partly due to its excellent electron transport material and high mobility $[26,27]$. It was also broadly used in OLEDs displays.

(5) Lithium fluoride ( $\mathrm{LiF})$ and aluminum (Al) were used as a cathode site.

2.2. Substrate and Solution Preparation. ITO substrate was immersed into ultrasonic bath for $15 \mathrm{~min}$ using acetone, followed by ethanol. DI water was finally used to remove any contaminants. The substrates were then blown with $\mathrm{N}_{2}$ gas to dry it. After that, 26DCzPPy and FIrpic $15 \mathrm{wt} \%$ were dissolved by chlorobenzene as an emitting layer, whereas TPBi of $0.15 \mathrm{wt} \%$ was dissolved by chloroform. Solution was stirred on a hot plate for $30 \mathrm{~min}$ to dissolve all the ingredients. Final solution was white and clear appearances without any suspension of the particles. On the other hand, PET release film (RF) with silicone as release agent was used as a stamp. It was made of polyethylene terephthalate (PET) as carrier, high temperature resistance (up to $210^{\circ} \mathrm{C}$ ), and good flexibility. RF was cut into an appropriate dimension $\left(1.5 \times 1.5 \mathrm{~cm}^{2}\right)$. RF was hence contacted on polydimethylsiloxane (PDMS) at the same size as a stamp.

2.3. Deposition of TPBi Thin Film Using RF Stamp Printing. PEDOT:PSS was firstly spin-coated onto ITO substrate $(3500 \mathrm{rpm}, 15 \mathrm{sec})$. It was then baked on a hot plate at $120^{\circ} \mathrm{C}$ for $20 \mathrm{~min}$. The TPBi $0.15 \mathrm{wt} \%$ in chloroform was therefore spin-coated $(3500 \mathrm{rpm}, 5 \mathrm{sec})$ onto the RF surface. Subsequently, a thin TPBi was deposited on a surface of ITO substrate by attaching PDMS/RF/TPBi film on a sample under a specific temperature, pressure, and time. After that, the whole system was cooled down to room temperature and carefully peeled PDMS/RF out and left the TPBi with uniform distribution on a device. The elevated temperature was beneficial of completing transfer of the thin film from the stamp to the substrate and hence enables a high-yield process $[9,28,29]$. The fabrication steps of TPBi thin films were displayed in Figure 1. Optical measurement under a range of UV-Vis region was carried out using a UV-Vis spectrometer (model: AVANTES).

2.4. Fabrication of Blue OLEDs Using RF Stamp Printing. Solution process of OLEDs was begun with spin-coating PEDOT:PSS onto ITO-coated PEN substrate. After spincoating was over, this sample was immediately treated by heating on a hot plate at $120^{\circ} \mathrm{C}$ for $20 \mathrm{~min}$ to eliminate the residual solution. Then it was taken out of a hot plate to decrease the temperature, awaiting for the deposition of the next layer. EML was then spin-coated onto PEDOT:PSS layer to form $45 \mathrm{~nm}$ thickness. Subsequently, sample was directly put onto a hot plate at $100^{\circ} \mathrm{C}$ for $15 \mathrm{~min}$ to improve the properties of the organic film. RF stamp was subsequently used to transfer TPBi film onto EML surface. TPBi film was formed onto RF surface via spin-coating. After that, the stamp printing process was carried out by attaching the PDMS/RF/TPBi film on EML under different temperatures and times as shown in Figure 1. The stamp was peeled away from the substrate to complete the printing process. Finally, $\mathrm{LiF}$ and $\mathrm{Al}$ were thermally evaporated as a cathode side. Final structure of the resulting device was ITO/ spin-PEDOT:PSS $(100 \mathrm{~nm}) /$ spin-TCTA:26DCzPPy:FIrpic $(45 \mathrm{~nm}) / \mathrm{RF}$ stamping-TPBi $(35 \mathrm{~nm}) / \mathrm{LiF} / \mathrm{Al}(0.8 / 150 \mathrm{~nm})$. The energy band diagram of our materials was shown in Figure 2. The devices were measured by a PR650 spectra scan spectrometer and Keithley 2400 voltage-current source.

\section{Results and Discussion}

3.1. Absorption. Transferred TPBi thin films at the different thicknesses are investigated by UV-Vis spectrometer in which 


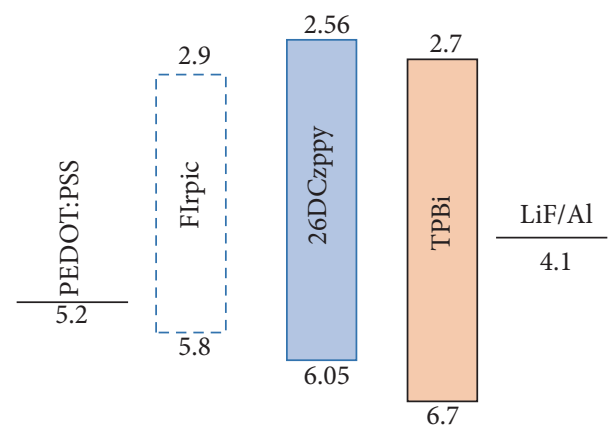

FIgURE 2: Energy band diagram of materials under this study.

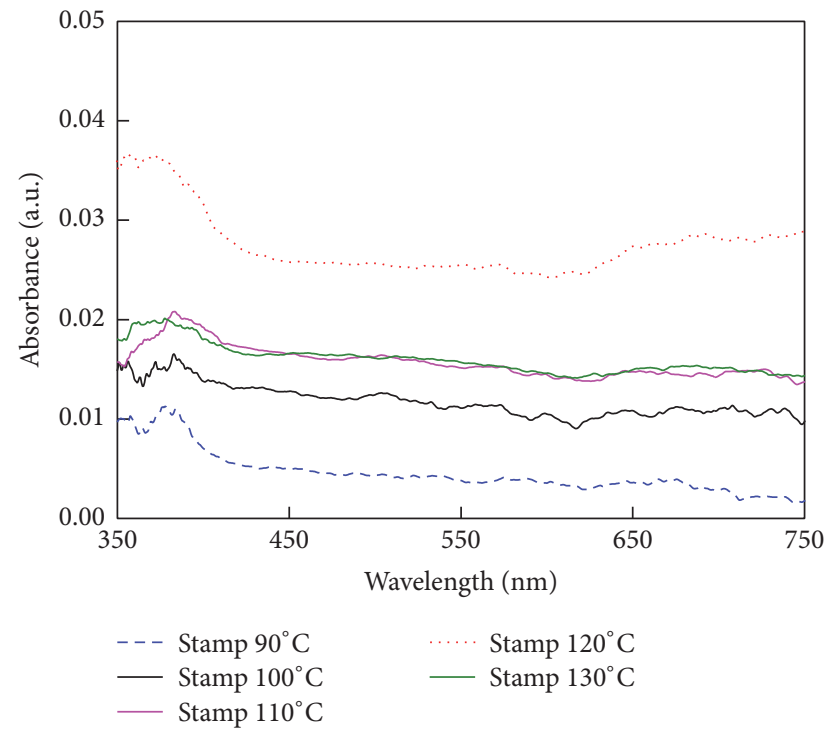

Figure 3: Absorption spectra of TPBi film in different stamping temperatures.

the obtained thickness depends on the stamping temperatures and times (under a constant load of $6 \mathrm{~N}$ ). Absorption of the films as a function of stamp temperature (under a constant time of $100 \mathrm{sec}$ ) is shown in Figure 3. The film shows large absorbance in UV wavelength. Peak absorbance of the film at $390 \mathrm{~nm}$ is attributable to $\pi-\pi^{*}$ transition [30]. The small and broad absorption of the film around $560 \mathrm{~nm}$ is assigned to its well ordered structure and freecarrier absorption, revealing a semiconducting nature of TPBi film [31]. Peak absorbance versus stamping temperature is therefore plotted in Figure 4. It is found that the optimum film thickness is achieved if the stamp printing temperature is $120^{\circ} \mathrm{C}$. On the other hand, absorption of the film as a function of stamp printing time (under a constant temperature of $120^{\circ} \mathrm{C}$ ) is shown in Figure 5. The film shows large absorbance in UV regime. Peak absorbance versus stamping time is therefore plotted in Figure 6. It is seen that the optimum film thickness is achieved if the stamp printing time is $120 \mathrm{sec}$.

3.2. Morphology. Morphology of TPBi thin film is characterized using AFM as it results in the device performances [32].

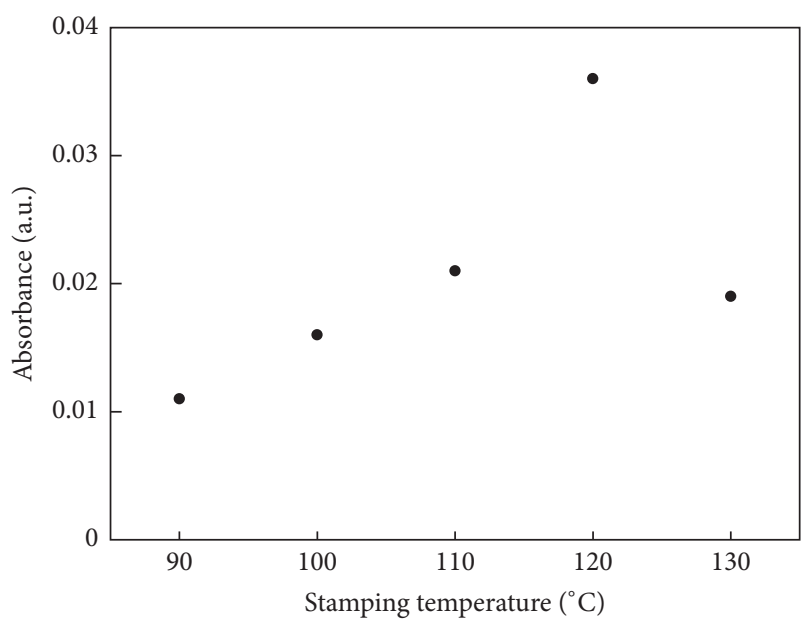

Figure 4: Peak absorbance at $390 \mathrm{~nm}$ of TPBi as a function of stamping temperature.

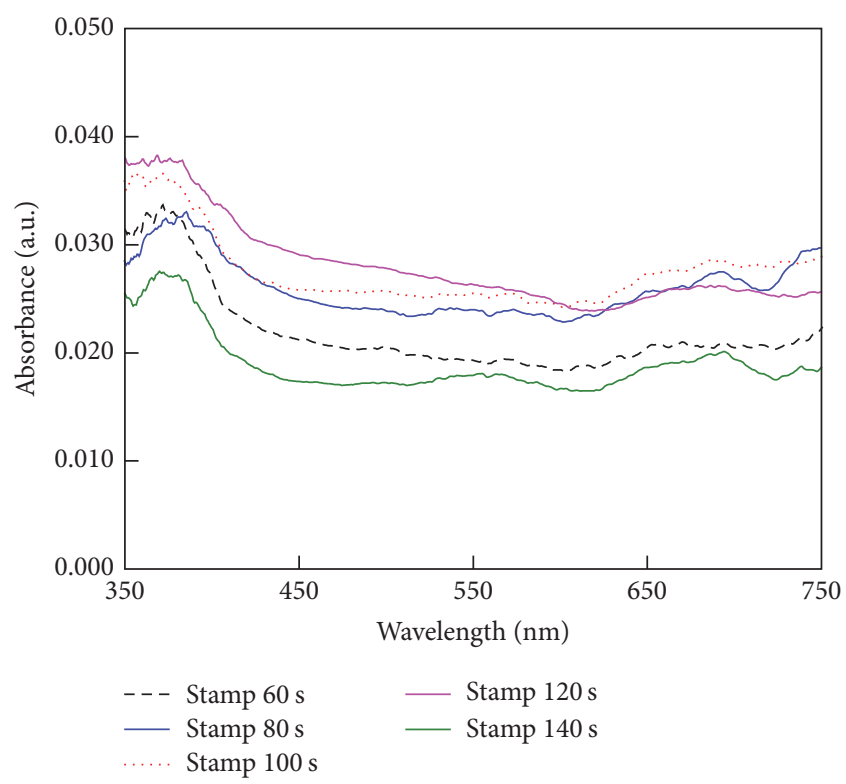

FIGURE 5: Absorption spectra of TPBi in different stamping times.

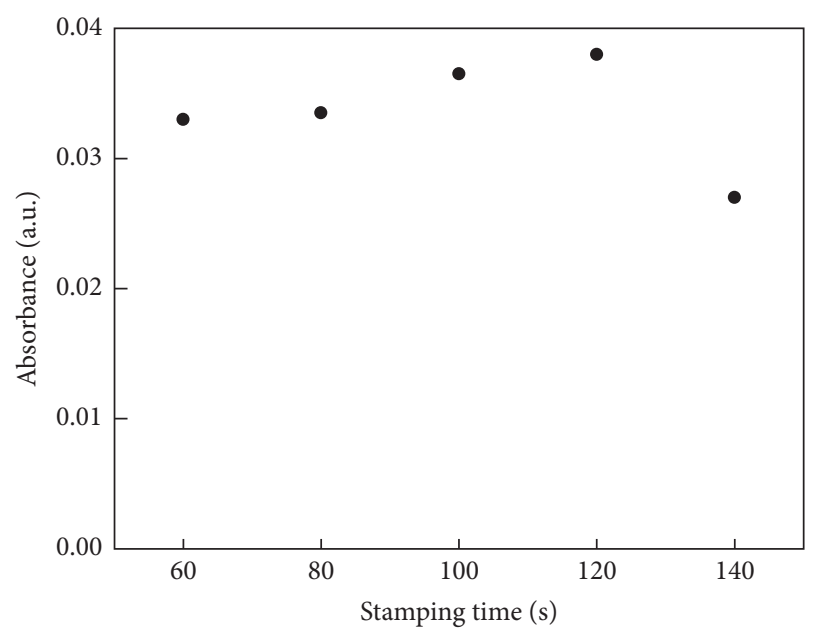

FIgUre 6: Peak absorbance at $390 \mathrm{~nm}$ of TPBi film as a function of stamping times. 


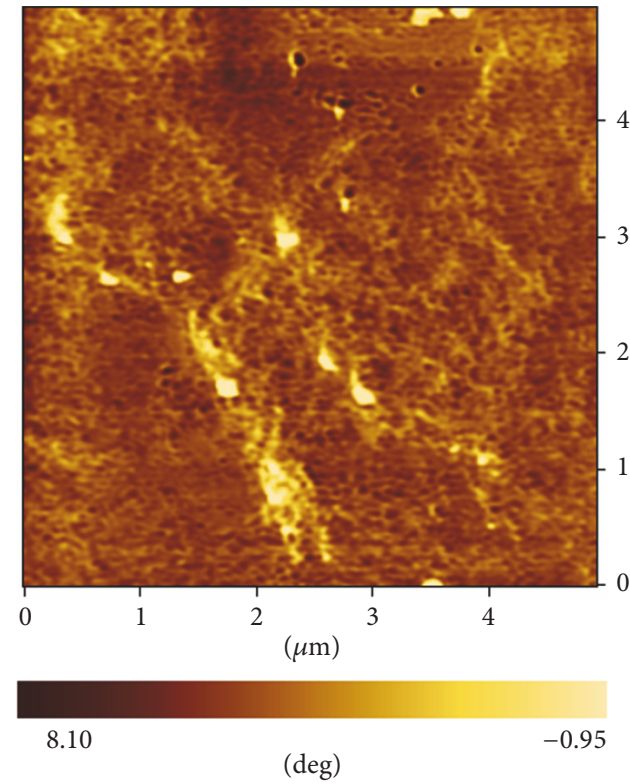

(a)

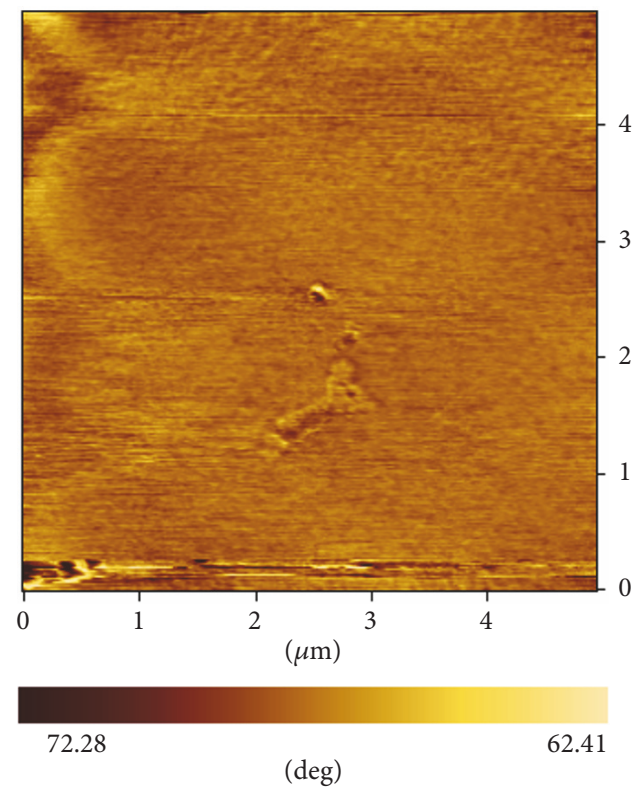

(c)

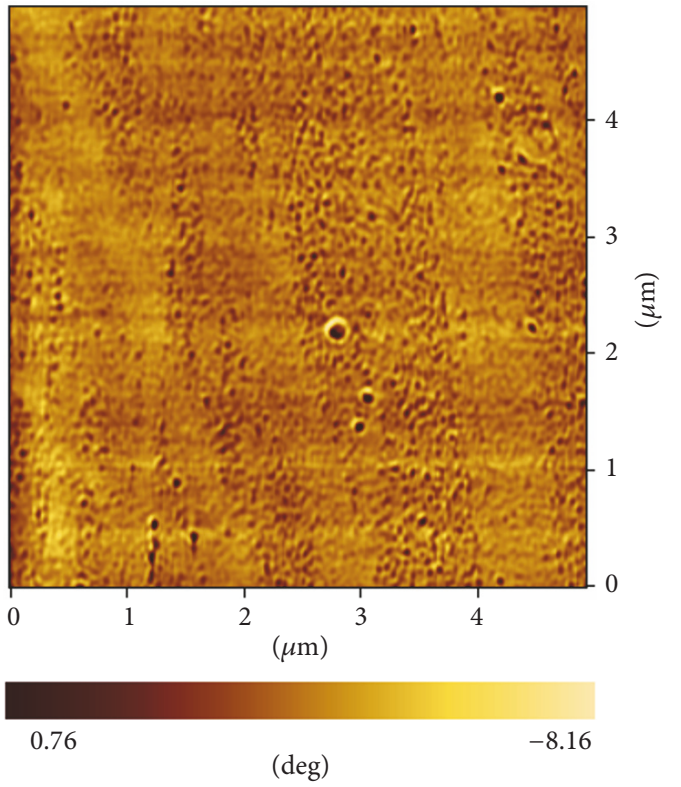

(b)

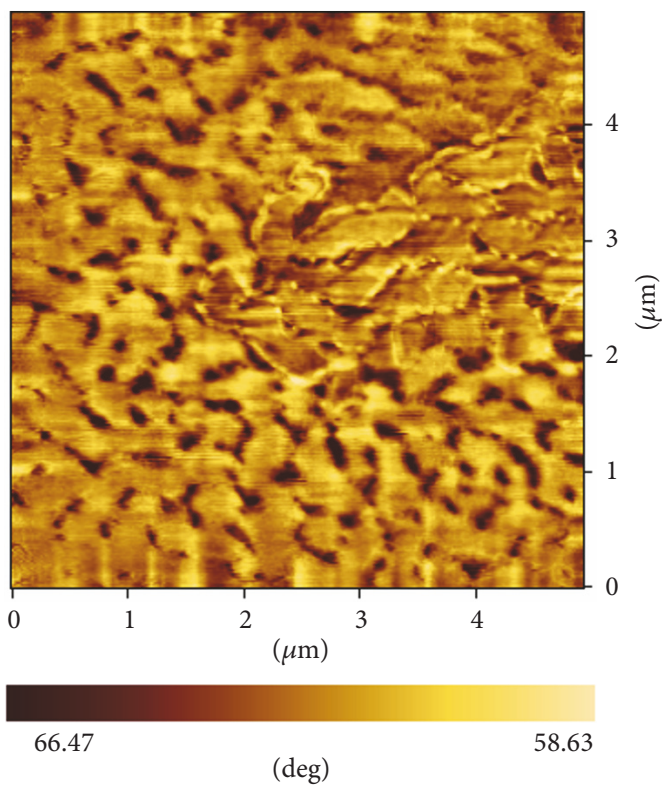

(d)

FIgURE 7: AFM images of the organic thin films: (a) PEDOT:PSS, (b) PEDOT:PSS/spin TPBi, (c) release film/spin TPBi, and (d) PEDOT:PSS/RF stamp TPBi.

To check the surface roughness of the film, the specimen with dimension of $5 \mu \mathrm{m} \times 5 \mu \mathrm{m}$ is scanned under the tapping mode. Figure 7 illustrates AFM images of PEDOT:PSS, PEDOT:PSS/spin TPBi, RF/spin TPBi, and PEDOT:PSS/RF stamp TPBi film. AFM images of the film onto the RF before and after transferring from the substrates are seen in Figures 7(c) and 7(d), respectively. The TPBi thin film from RF donor is reproducibly transferred without any critical film fractures. There is a bit different mean surface roughness between spincoated and stamp printed films. Roughness root mean square of PEDOT:PSS, PEDOT:PSS/spin TPBi, RF/spin TPBi, and PEDOT:PSS/RF stamp TPBi film is $10.85,0.56,0.72$, and $3.64 \mathrm{~nm}$, respectively. They show similar morphology; even some spikes are seen in spin-coated films. The TPBi film printed from RF stamp shows a smooth surface, resulting in the low surface roughness. This explains that the TPBi film morphology of spin-coated TPBi film is not affected by the stamp printing process. Smooth surface film morphology is kept during processing. It demonstrates that a TPBi film can be fabricated effectively not only by the spin-coating process 


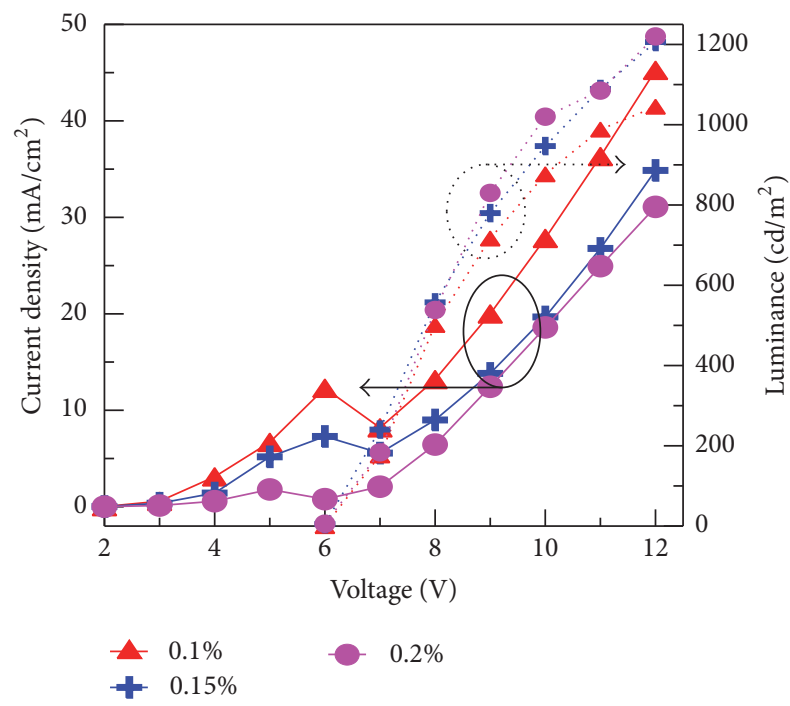

Figure 8: Current density and luminance characteristics as a function of the applied voltage.

but also by the RF stamp printing process. This indicates that our deposition of TPBi film by using the RF stamp printing process is successfully achieved. It is therefore expected that the device performances might not be degraded by the RF stamp printing technique.

3.3. Electrical Properties. In order to evaluate the properties of the TPBi thin film in OLEDs device, the structure of the following layers, PEN/ITO/spin-PEDOT:PSS/RF stamp$\mathrm{TPBi} /$ spin-EML/LiF/Al, is fabricated. To understand the effect of RF stamp printed TPBi on the characteristics of the devices, we select three concentrations of TPBi to fabricate three kinds of devices; namely, TPBi concentration of $0.1 \%$ is device A, $0.15 \%$ is device $\mathrm{B}$, and $0.2 \%$ is device $\mathrm{C}$. The concentration of TPBi is diluted by solvent. The thickness of TPBi is decreased which in turn affects the $J-V-L$ characteristics of the devices. As seen with solid lines in Figure 8, at a certain driving voltage, the current density somewhat enhances when TPBi concentration decreases from $0.2 \%$ to $0.1 \%$. Reduction of current density and enhancement of turnon voltage possibly comes from the enhancing of TPBi thickness. Further increasing TPBi concentration results in the high performance. For instance, the luminance and efficiency of the devices are enhanced from $695 \mathrm{~cd} / \mathrm{m}^{2}(3.5 \mathrm{~cd} / \mathrm{A})$ to $900 \mathrm{~cd} / \mathrm{m}^{2}(4.5 \mathrm{~cd} / \mathrm{A})$ and $1250 \mathrm{~cd} / \mathrm{m}^{2}(6.3 \mathrm{~cd} / \mathrm{A})$ when the TPBi concentration increases from $0.1 \%$ to $0.15 \%$ and $0.2 \%$, respectively, as shown with dotted lines in Figure 8 and with solid lines in Figure 9. It is clearly seen that the concentration of TPBi results in the thickness and the film quality of the stamping film which in turn affects the charge balance of the devices.

\section{Conclusions}

We have demonstrated that PET release film can be used as the stamp for the printing organic thin films. TPBi electron

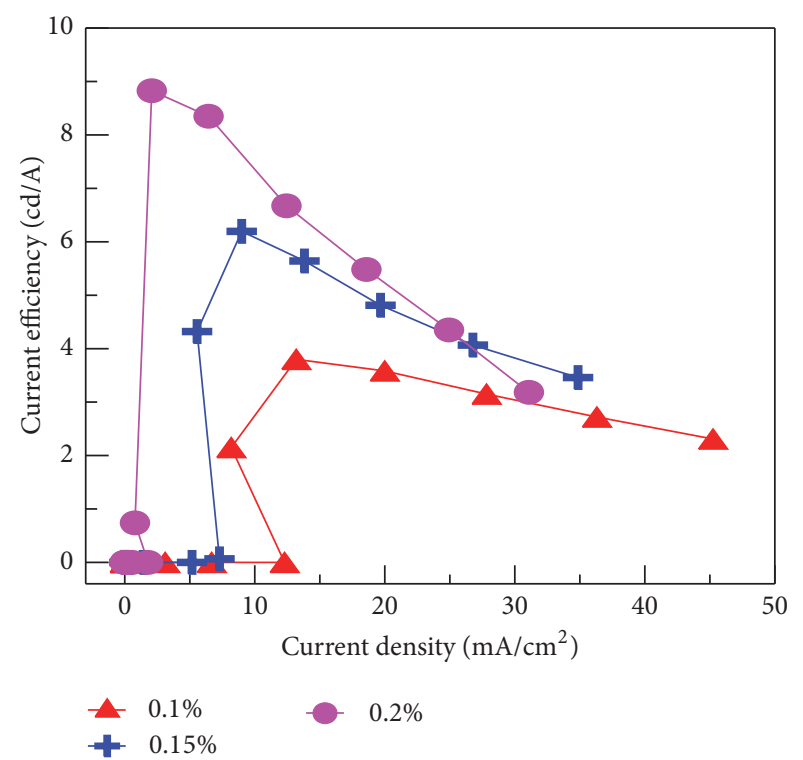

FIGURE 9: Current efficiency characteristics as a function of the current density.

transport layer of organic light-emitting diodes is produced using PET release film-based printing with a good uniformity printing area of $1.5 \times 1.5 \mathrm{~cm}^{2}$. Optical properties and morphology of TPBi thin film are improved via temperature and time of the stamp printing process. Together, our results serve as a firm foundation for exploring PET release film-based printing in the deposition of multilayer of OLED displays. It is very useful in potential applications for the low-cost electroluminescent devices in the solid-state lighting and large-area light sources. Overall, these results demonstrate that PET release film as the stamp offers an attractive option for printing organic thin layers in OLEDs devices. Further attempts will concentrate on improvements of a full device including application for high efficiency OLEDs.

\section{Conflicts of Interest}

There are no conflicts of interest in this paper.

\section{Acknowledgments}

This work is supported by King Mongkut's Institute of Technology Ladkrabang (KREF145901).

\section{References}

[1] Q. Wang, J. Ding, M. Dongge et al., "Harvesting excitons via two parallel channels for efficient white organic LEDs with nearly $100 \%$ internal quantum efficiency: fabrication and emissionmechanism analysis," Advanced Functional Materials, vol. 19, no. 1, pp. 84-95, 2009.

[2] H. Uoyama, K. Goushi, K. Shizu, H. Nomura, and C. Adachi, "Highly efficient organic light-emitting diodes from delayed fluorescence," Nature, vol. 492, no. 7428, pp. 234-238, 2012. 
[3] S. Sivaramakrishnan, M. Zhou, A. C. Kumar et al., "Solutionprocessed conjugated polymer organic p-i-n light-emitting diodes with high built-in potential by solution- and solid-state doping," Applied Physics Letters, vol. 95, Article ID 213303, 2006.

[4] Z.-L. Zhou, X. Sheng, K. Nauka et al., "Multilayer structured polymer light emitting diodes with cross-linked polymer matrices," Applied Physics Letters, vol. 96, no. 1, Article ID 013504, 2010.

[5] K. Meerholz, "Device physics: enlightening solutions," Nature, vol. 437, no. 7057, pp. 327-328, 2005.

[6] D. An, J. Zou, H. Wu, J. Peng, W. Yang, and Y. Cao, "White emission polymer light-emitting devices with efficient electron injection from alcohol/water-soluble polymer/Al bilayer cathode," Organic Electronics: Physics, Materials, Applications, vol. 10, no. 2, pp. 299-304, 2009.

[7] N. Rehmann, D. Hertel, K. Meerholz, H. Becker, and S. Heun, "Highly efficient solution-processed phosphorescent multilayer organic light-emitting diodes based on small-molecule hosts," Applied Physics Letters, vol. 91, no. 10, Article ID 103507, 2007.

[8] Q. Sun, D. W. Chang, I. Dai, J. Grote, and R. Naik, "Multilayer white polymer light-emitting diodes with deoxyribonucleic acid-cetyltrimetylammonium complex as a holetransporting/electron-blocking layer," Applied Physics Letters, vol. 92, Article ID 251108, 3 pages, 2008.

[9] K.-H. Yim, Z. Zheng, Z. Liang, R. H. Friend, W. T. S. Huck, and J.-S. Kim, "Efficient conjugated-polymer optoelectronic devices fabricated by thin-film transfer-printing technique," Advanced Functional Materials, vol. 18, no. 7, pp. 1012-1019, 2008.

[10] J. Choi, K. H. Kim, S. J. Choi, and H. H. Lee, "Whole device printing for full color displays with organic light-emitting diodes," Nanotechnology, vol. 17, pp. 2246-2249, 2006.

[11] T. A. M. Ferenczi, J. Nelson, C. Belton et al., "Planar heterojunction organic photovoltaic diodes via a novel stamp transfer process," Journal of Physics Condensed Matter, vol. 20, no. 47, Article ID 475203, 8 pages, 2008.

[12] L. Chen, P. Degenaar, and D. D. C. Bradley, "Polymer transfer printing: application to layer coating, pattern definition, and diode dark current blocking," Advanced Materials, vol. 20, no. 9, pp. 1679-1683, 2008.

[13] S.-Z. Chen, S.-H. Peng, T.-Y. Ting et al., "Organic light-emitting diodes with direct contact-printed red, green, blue, and white light-emitting layers," Applied Physics Letters, vol. 101, no. 15, Article ID 153304, 4 pages, 2012.

[14] T. H. Park, Y. W. Park, J. H. Choi et al., "Contact printing of the emitting layer for high performance multilayered phosphorescent organic light-emitting diodes," Organic Electronics: Physics, Materials, Applications, vol. 12, no. 6, pp. 1063-1067, 2011.

[15] C. Y. Hui, A. Jagota, Y. Y. Lin, and E. J. Kramer, "Constraints on microcontact printing imposed by stamp deformation," Langmuir, vol. 18, no. 4, pp. 1394-1407, 2002.

[16] J. K. Hwang, S. Cho, J. M. Dang et al., "Direct nanoprinting by liquid-bridge-mediated nanotransfer moulding," Nature Nanotechnology, vol. 5, no. 10, pp. 742-748, 2010.

[17] X.-M. Li, M. Péter, J. Huskens, and D. N. Reinhoudt, "Catalytic microcontact printing without ink," Nano Letters, vol. 3, no. 10, pp. 1449-1453, 2003.

[18] M. J. Owen and P. J. Smith, "Plasma treatment of polydimethylsiloxane," Journal of Adhesion Science and Technology, vol. 8, no. 10, pp. 1063-1075, 1994.

[19] B. Olander, A. Wirsén, and A.-C. Albertsson, "Oxygen microwave plasma treatment of silicone elastomer: kinetic behavior and surface composition," Journal of Applied Polymer Science, vol. 91, no. 6, pp. 4098-4104, 2004.

[20] S. Khan, L. Lorenzelli, and R. S. Dahiya, "Technologies for printing sensors and electronics over large flexible substrates: a review," IEEE Sensors Journal, vol. 15, no. 6, pp. 3164-3185, 2015.

[21] T. Kaufmann and B. J. Ravoo, "Stamps, inks and substrates: Polymers in microcontact printing," Polymer Chemistry, vol. 1, no. 4, pp. 371-387, 2010.

[22] J. Huang, P. F. Miller, J. S. Wilson, A. J. de Mello, J. C. de Mello, and D. D. Bradley, "Investigation of the effects of doping and post-deposition treatments on the conductivity, morphology, and work function of poly(3,4-ethylenedioxythiophene)/poly(styrene sulfonate) films," Advanced Functional Materials, vol. 15, no. 2, pp. 290-296, 2005.

[23] T. M. Brown, J. S. Kim, R. H. Friend, F. Cacialli, R. Daik, and W. J. Feast, "Built-in field electroabsorption spectroscopy of polymer light-emitting diodes incorporating a doped poly(3,4-ethylene dioxythiophene) hole injection layer," Applied Physics Letters, vol. 75, no. 12, pp. 1679-1681, 1999.

[24] S.-J. Su, E. Gonmori, H. Sasabe, and J. Kido, "Highly efficient organic blue-and white-light-emitting devices having a carrierand exciton-confining structure for reduced efficiency roll-off," Advanced Materials, vol. 20, no. 21, pp. 4189-4194, 2008.

[25] C. Cai, S.-J. Su, T. Chiba et al., "High-efficiency red, green and blue phosphorescent homojunction organic light-emitting diodes based on bipolar host materials," Organic Electronics: Physics, Materials, Applications, vol. 12, no. 5, pp. 843-850, 2011.

[26] S. H. Kim, J. Jang, and J. Y. Lee, "Relationship between host energy levels and device performances of phosphorescent organic light-emitting diodes with triplet mixed host emitting structure," Applied Physics Letters, vol. 91, no. 8, Article ID 083511, 2007.

[27] M. E. Kondakova, T. D. Pawlik, R. H. Young et al., "Highefficiency, low-voltage phosphorescent organic light-emitting diode devices with mixed host," Journal of Applied Physics, vol. 104, no. 9, Article ID 094501, 2008.

[28] X. Feng, M. A. Meitl, A. M. Bowen, Y. Huang, R. G. Nuzzo, and J. A. Rogers, "Competing fracture in kinetically controlled transfer printing," Langmuir, vol. 23, no. 25, pp. 12555-12560, 2007.

[29] M. J. Allen, V. C. Tung, L. Gomez et al., "Soft transfer printing of chemically converted graphene," Advanced Materials, vol. 21, no. 20, pp. 2098-2102, 2009.

[30] M. Neghabi, M. Zadsar, and S. M. B. Ghorashi, "Investigation of structural and optoelectronic properties of annealed nickel phthalocyanine thin films," Materials Science in Semiconductor Processing, vol. 17, pp. 13-20, 2014.

[31] S. R. Ovshinsky and D. Adler, "Local structure, bonding, and electronic properties of covalent amorphous semiconductors," Contemporary Physics, vol. 19, no. 2, pp. 109-126, 1978.

[32] C. W. Joo, S. O. Jeon, K. S. Yook, and J. Y. Lee, "Improved device performances in polymer light-emitting diodes using a stamp transfer printing process," Organic Electronics: Physics, Materials, Applications, vol. 10, no. 2, pp. 372-375, 2009. 

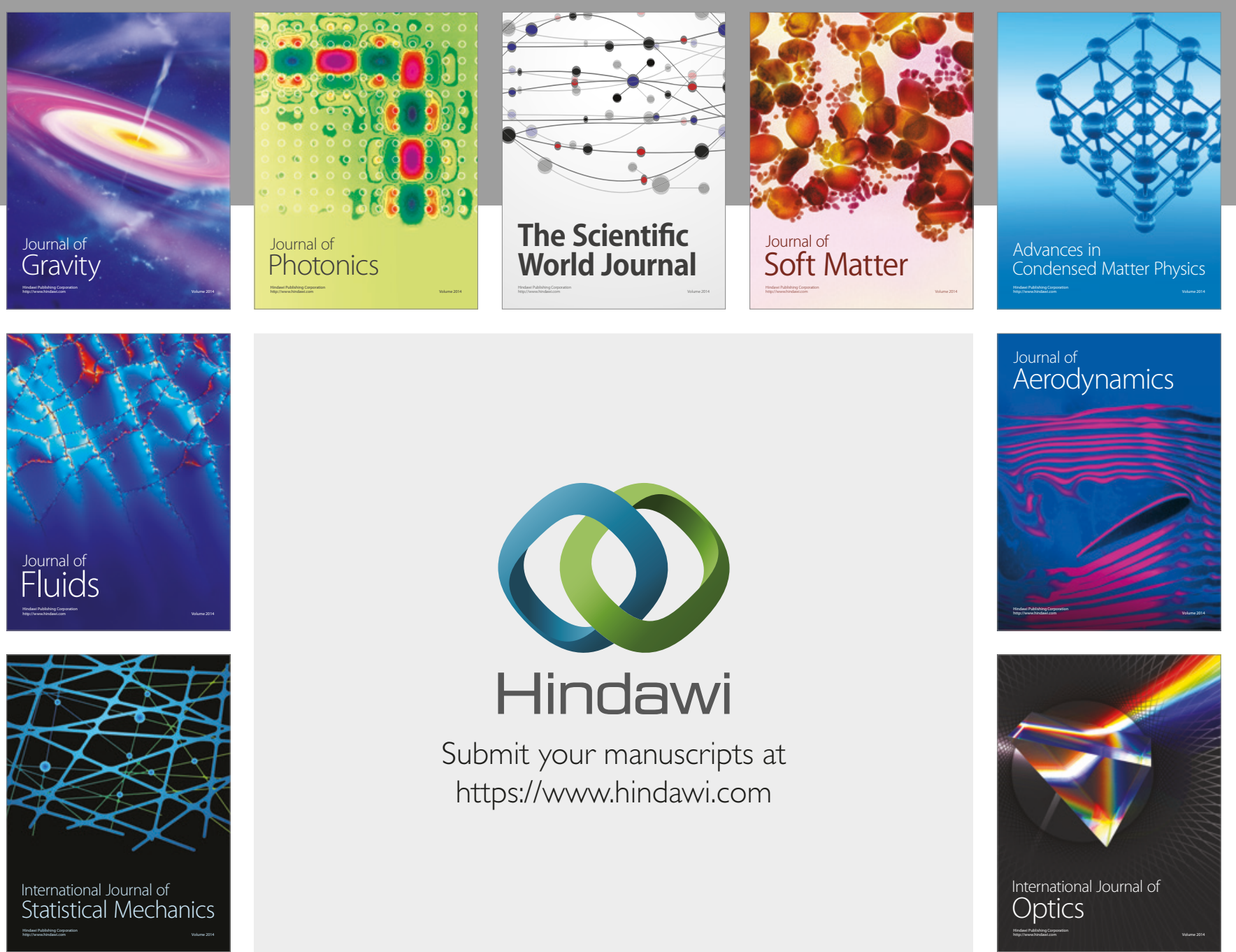

Submit your manuscripts at

https://www.hindawi.com
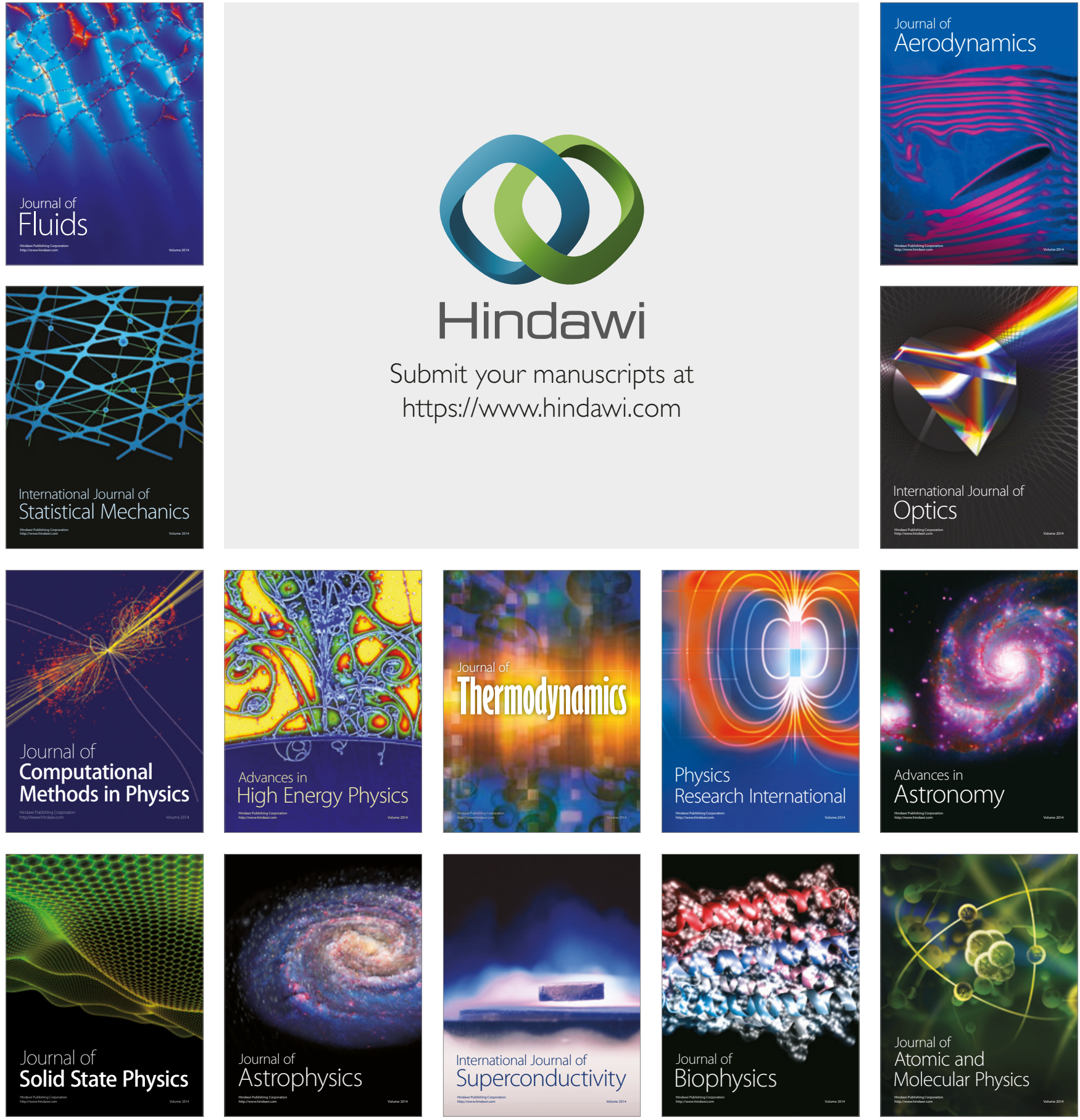